Revista de Derecho núm. 56 (202I): I-33

ARTíCULOS DE INVESTIGACIÓN

\title{
La vivienda del deudor persona natural en el procedimiento concursal chileno y reflexiones para su protección
}

\author{
The home of the natural person debtor in the Chilean bankruptcy \\ procedure and reflections for its protection
}

\author{
Miguel Ángel Alarcón Cañuta \\ Universidad Arturo Prat, Chile
}

\begin{abstract}
RES UMEN
El trabajo tiene por objetivo analizar el tratamiento de la vivienda del deudor en el procedimiento concursal de persona natural chileno y proponer argumentos iniciales que permitan orientar su protección. En base a una metodología comparada, que arroja luces respecto del tratamiento del problema en ordenamientos comparados, y a través del método dogmático, se resalta la necesidad de otorgar protección al inmueble que se constituye en vivienda del deudor, y se ofrece una propuesta de tratamiento protector del inmueble en el procedimiento concursal en atención a la finalidad de la regulación concursal de la persona natural.
\end{abstract}

\section{PALABRAS CLAVE}

Vivienda del deudor - deudor persona natural - procedimiento concursal . cramdown $\cdot$ exención al activo concursal.

\section{ABSTRACT}

The objective of the work is to analyze the treatment of the debtor's home in the Chilean natural person bankruptcy procedure and to propose initial arguments that allow guiding their protection. Based on a comparative methodology, which gives lights on the treatment of the problem in comparative legal systems, and through the dogmatic method, the need to grant protection to the property that is the debtor's home is highlighted, and a proposal for the protective treatment of the property is offered in the bankruptcy procedure in attention to the purpose of the bankruptcy regulation of the natural person.

KEY WORDS

Debtor's home $\cdot$ natural person debtor $\cdot$ bankruptcy procedure $\cdot$ cramdown . exemption to the bankruptcy assets. 


\section{INTRODUCCIÓN}

La vivienda representa el mayor activo de las familias chilenas y, paradójicamente, una importante fuente de endeudamiento. En el año 20I7, el $63 \%$ de los hogares en Chile tiene vivienda principal, mientras que el $21 \%$ tiene una deuda hipotecaria. ${ }^{1}$ En 2019 , el $55 \%$ de las deudas de los hogares chilenos correspondía a deuda hipotecaria para la vivienda, ${ }^{2}$ y en 2020, la deuda de hogares estaba constituida en gran medida por créditos bancarios para la vivienda (28,8\% del PIB). ${ }^{3}$ En 2018 , el 22,7\% de los deudores tenía una carga financiera superior al 50\% de sus ingresos y el $32, \mathrm{I} \%$, una superior al $40 \%{ }^{4}$ En 2020 , tales porcentajes alcanzaron el $\mathrm{I} 6 \%$ y $23,4 \%$, respectivamente. ${ }^{5}$ En 2019 se informó que un $25 \%$ de los deudores bancarios presentaba cargas financieras que más que duplicaban la carga mediana (19,9\%), con niveles de apalancamiento 3,6 veces superior al nivel mediano $(3,7 \%),{ }^{6}$ y que de los ingresos disponibles anuales de una persona el $75 \%$ se destina a deudas. ${ }^{7}$ En 2020, el apalancamiento alcanzó a 3,66, y en el tramo de personas entre 35 a 40 ańos, llegó a $7,93,{ }^{8}$ mientras que el porcentaje de deuda de los hogares sobre sus ingresos disponibles a octubre del mismo año alcanzó $76,4 \%{ }^{9}$

Independiente de las discusiones que puedan generarse sobre las causas del excesivo endeudamiento de las familias, vinculadas al modelo económico, ${ }^{\mathrm{IO}}$ al nivel de responsabilidad del mercado del crédito al otorgar

${ }^{1}$ Encuesta Financiera de Hogares 2017 (2018), pp. I2 y 20.

${ }^{2}$ Informe Loan to Value Residencial (LTV): Estadísticas en Series de Tiempo (2019), p. 4.

3 Cuentas Nacionales de Chile (2020), p. 32

${ }_{4}$ Informe de Endeudamiento (20I8), p. IO.

5 Informe de Endeudamiento (2020), p. I2.

${ }^{6}$ Informe de Endeudamiento (2019), p. 4.

7 Cuentas Nacionales por Sector Institucional (2019), p. 4.

${ }^{8}$ Informe de Endeudamiento (2020), p. I6.

9 Cuentas Nacionales por Sector Institucional, Segundo trimestre (2020), p. 5 .

1o Sobre la noción de gubernamentalidad financiera, GonzÁLez, Felipe, Crédito, deuda y gubernamentalidad financiera en Chile, en Revista Mexicana de Sociología 80 (2018) 4, pp. 883 ss. Sobre financiarización de la vida cotidiana y la subjetivización que genera, PÉRez-RoA, Lorena y Gómez, Matías, Deuda, temporalidad y moralidad: Proceso de subjetivación de parejas jóvenes profesionales, en Psicoperspectivas I8 (2019) 3, pp. 3 ss.; Marambio, Alejandro, Endeudamiento "saludable», empoderamiento y control social, en Polis, Revista Latinoamericana (2018) 42, pp. 8I-82. Dando cuenta del impacto del modelo económico en la construcción de mentalidades e imaginarios sociales que orientan y modelizan la conducta personal y colectiva, Denegri, Marianela, Cabezas, Daniel, del Valle, Carlos, GonzÁlez, Yéssica y Sepúlveda, Jocelyne, Escala de actitudes hacia el endeudamiento: 
crédito, ${ }^{\text {II }} \mathrm{o}$ al grado de diligencia del consumidor ${ }^{\text {I2 }}$ un exceso de deudas y altos niveles de morosidad, que aumentan en épocas de crisis económicas globales con ocasión de sus efectos en la empresa y el empleo, inciden en el aumento de las situaciones de insolvencia de los deudores personas naturales. Como ejemplo, si a diciembre de 2019 las solicitudes o demandas de liquidación concursal fueron 4.734, al mismo mes de 2020 el total alcanzó las 5.113.$^{13}$

Con ocasión del procedimiento concursal de liquidación, y en caso de que no se logre un acuerdo en la audiencia de renegociación en un procedimiento concursal homónimo, la realización de los bienes del deudor para pagar a los acreedores repercute en la pérdida de la vivienda. Ello conlleva en muchos casos la pérdida del único bien que el núcleo familiar tiene para proyectar su desarrollo en el ámbito económico y social, imponiendo condiciones desmejoradas de subsistencia, desprotección y abandono, ${ }^{14}$ problemas psicosociales en los miembros del grupo familiar ${ }^{15}$

validez factorial y perfiles actitudinales en estudiantes universitarios chilenos, en Universitas Psychologica. Panamerican Journal of Psychology II (2012) 2, p. 506. En materia de tarjetas de crédito, Goldenberg, Juan Luis, El necesario ajuste de la asignación del riesgo de sobreendeudamiento en la regulación de las tarjetas de crédito: desde un sistema basado en los deberes de información a un modelo de corresponsabilidad, en Revista de Derecho (Pontificia Universidad Católica de Valparaíso) 49 (2017) 2, pp. 57 y 58.

II Informe Endeudamiento Nacional (20I5), pp. I y 4. Sobre el punto de la responsabilidad del prestamista, Alarcón, Miguel, El deber de evaluación de la solvencia del deudor persona natural por el prestamista y su necesaria implementación en el ordenamiento jurídico chileno. Propuesta interpretativa para su reconocimiento, en IsLER, Erika (directora), GPS de Derecho de Consumo (Valencia, Tirant lo Blanch, 202I), en prensa; Goldenberg, Juan Luis, El sobreendeudamiento y los paradigmas del consumidor financiero responsable y del proveedor financiero profesional, en Ius et Praxis 26 (2020) I.

${ }_{12}$ Sobre el particular, especialmente en relación con la noción de sobreendeudamiento activo y pasivo, Alarcón, Miguel, La deuda por obligación constituida a través de crédito con aval del estado no constituye excepción al discharge en el ordenamiento jurídico chileno, en Revista Chilena de Derecho Privado (2018) 3I, pp. 28 y 29; Goldenberg, cit. (n. iI), p. 3; Bozzo, Sebastián, Sobreendeudamiento del consumidor en Chile: una revisión a la luz del derecho europeo, en Revista de Derecho (Valdivia) 33 (2020) I, p. 164. Aproximaciones a las causas planteadas, en Ruz, Gonzalo, Nuevo derecho concursal chileno (Santiago, Thomson Reuters, 2017), I, pp. 502 ss.

13 Boletín Estadístico Mensual, diciembre 2019 y diciembre 2020, Superintendencia de Insolvencia y Reemprendimiento.

${ }^{14}$ Equipo de Investigación Facultad de Psicología de la Universidad de Granada y Escuela Andaluza de Salud Pública, Estado de salud de la población afectada por un proceso de desahucio (2014) [visible en: https://bit.ly/3zJAuos], p. 6.

is Pevalian, D. J., Housing repossessions, evictions and common mental illness in the UK: results from a household panel study, en J Epidemiol Community Health 63 (2009), p. 950. 
y aumento del riesgo de exclusión social. ${ }^{16}$ Desde el punto de vista concursal, se constata que no existen en el ámbito nacional estudios o reflexiones vinculadas al tratamiento que el ordenamiento efectúa de la vivienda del deudor concursado.

Este artículo tiene por objeto analizar el tratamiento que el ordenamiento concursal chileno otorga a la vivienda del deudor en el concurso de acreedores de la persona natural, con especial énfasis en la vivienda adquirida a través de crédito hipotecario. A través de la comprensión de ciertas instituciones concursales y el tratamiento que ordenamientos comparados otorgan a la vivienda del deudor concursado, se entregan argumentos iniciales que permitan orientar la configuración de una institución concursal protectora de la vivienda del deudor y su familia.

\section{LA VIVIENDA DEL DEUDOR PERSONA NATURAL EN LA LEY 20.720}

\section{El tratamiento de la vivienda en el concurso del deudor persona natural}

El artículo 24I de la Ley 20.720 (LRLEP) aplica las normas de prelación de créditos del Título XLI del Libro IV del Código Civil para proceder al pago de los acreedores. Ahora bien, según el artículo 243 LRLEP, los acreedores hipotecarios se pagarán en la forma que determinan los artículos 2477 a 2480 del Código Civil. Debido a que la ley hace aplicables al procedimiento concursal de liquidación de la persona deudora gran parte de las normas de la liquidación de la empresa deudora, según el artículo I35 LRLEP, aplicable por el artículo 275, el acreedor hipotecario está facultado para iniciar o continuar su ejecución sobre el bien gravado con hipoteca a pesar de que la resolución de liquidación en el procedimiento concursal suspende las ejecuciones sobre los bienes del deudor; y según el artículo 280 de la LRLEP, el pago de los acreedores hipotecarios del deudor persona natural se efectuará en función de las normas del Código Civil señaladas.

Así, en caso de liquidación de la persona deudora, el acreedor hipotecario no tiene que esperar el resultado de la liquidación concursal, y puede ejecutar de inmediato el inmueble hipotecado (artículo I35 LRLEP). En

La pérdida de identidad del individuo producto de la pérdida de la vivienda de manera involuntaria,y otras consecuencias psicológicas, es descrita por Fox, Lorna, The meaning of home: a chimerical concept or a legal challenge?, en Journal of Law and Society 29 (2002) 4, pp. 599 y 602 ss.

${ }^{16}$ JimÉnez, Magdalena, Aproximación teórica de la exclusión social: complejidad e imprecisión del término. Consecuencias para el ámbito educativo, en Estudios Pedagógicos 34 (2008) I, p. I80. 
caso de existir más de un acreedor hipotecario, respecto del o los bienes hipotecados, podrá abrirse procedimiento concursal particular para que se les pague de inmediato con ella, según el orden de las fechas de las respectivas hipotecas. ${ }^{17}$

En este escenario, el Código Civil se pone en el lugar de que el producto de la realización del bien hipotecado alcance a cubrir el monto de la obligación garantizada. Ello se aprecia en el artículo 2479, que señala que en caso de que el acreedor hipotecario decida ejecutar individualmente la garantía, deberá consignar o afianzar una cantidad prudencial para cubrir los créditos de primera clase en la parte que sobre ellos recaiga, y restituir a la masa del concurso lo que sobrare después de cubiertas sus acciones.

Según el artículo 279 LRLEP, la realización del activo del deudor en el procedimiento de liquidación de persona deudora se regirá por la forma de realización simplificada o sumaria del artículo 204 de la misma ley. A pesar de lo señalado por la norma, surge la duda respecto de las reglas concretas que deberán aplicarse para la realización del inmueble, desde que el artículo 135 permite que el acreedor hipotecario pueda ejecutar separada e individualmente el inmueble, y sin esperar las resultas de la liquidación concursal de acuerdo con el artículo 2479 CC. El artículo I5o inciso segundo de la antigua Ley I8.I75 (de Quiebras), tras indicar que los acreedores hipotecarios se pagarían en la forma establecida en los artículos 2477 a 2480 CC, establecía que los concursos especiales hipotecarios que se formaren sin declaración de quiebra serían regidos por las normas del Código Civil y del Código de Procedimiento Civil (CPC), con lo que alguna doctrina entendía que si el concurso particular se abría con posterioridad al inicio de la quiebra, se regía por las normas de la Ley de Quiebras. ${ }^{18}$ En la ley actual, esta norma ya no se encuentra en el artículo 243, por lo que surge la duda tanto para el concurso particular de varios acreedores sobre una misma finca, como para la ejecución individual instada por el acreedor independiente al concurso. ${ }^{19}$

Podría estimarse que debido a que la ejecución del bien es independiente, ello implica que la realización se lleva a cabo fuera del ámbito

${ }^{17}$ En la legislación de quiebras antigua, Abeliuk, René, Las obligaciones (6. ${ }^{\text {a }}$ edición actualizada, Santiago, Thomson Reuters, 20I4), II, pp. II95 y II96, plantea los casos en que el acreedor podrá ejecutar de manera separada a pesar del inicio del procedimiento y el caso en que existan varios acreedores hipotecarios concurrentes en una misma finca.

${ }^{18}$ Abeliuk, cit. (n. I7), p. 1195 .

19 Según BAEza, Gonzalo, Derecho concursal chileno. Legislación vigente y reforma proyectada (Santiago, Thomson Reuters, 20I3), I, p. 156I, en la legislación anterior, la norma servía para aclarar la legislación aplicable a los concursos especiales hipotecarios. 
concursal, siendo aplicables las reglas generales de realización de bienes. ${ }^{20}$ Debido a que el artículo 243 LRLEP, en relación con los artículos 2477 y 2479 CC, consagrarían un derecho de ejecución del acreedor hipotecario fuera del concurso, la forma de realización de bienes de la persona deudora del artículo 204 no se aplicaría a los acreedores que hubieren optado por realizar de manera individual el inmueble.

Por otro lado, podría estimarse que aunque las normas se refieren a una facultad de ejecución independiente, dado que la ejecución se lleva a cabo en el contexto concursal, y debido a que las normas aludidas no se refieren a la forma de realización concreta, son aplicables las mismas reglas de realización sumaria o simplificada. ${ }^{21}$ Ello podría verse corroborado al comprenderse que los artículos 2477 y 2479 del Código Civil, al señalar respectivamente que "podrá» abrirse concurso particular a solicitud de los acreedores y que «no estarán obligados» a aguardar las resultas del concurso general, quieren decir que el acreedor hipotecario tendrá la facultad de escapar al acuerdo de la junta de acreedores respecto de la forma de realización, pero no en cuanto a las normas concursales de realización.

Respecto de la segunda interpretación, podría suceder que por aplicación del artículo 204, letra b), en relación con la letra e), el producto de la realización del bien inmueble sea mucho menor al valor de la deuda hipotecaria. Debido a que será el liquidador quien generará las bases del remate considerando las reglas del artículo 204, el valor inicial del inmueble podría alcanzar solo el avalúo fiscal, y de allí en más, podría incluso efectuarse el remate por valor del 50\% del fijado originariamente o, incluso, sin mínimo (artículo 204 letra e) LRLEP). En este contexto, debe notarse que esta situación no solo se producirá en caso de ejecución individual de un inmueble hipotecado, durante el concurso, sino de cualquier inmueble que sea parte del activo del deudor persona natural concursada.

En la primera interpretación surge la duda respecto del valor mínimo del inmueble de cara al remate, o en el caso de que el acreedor hipotecario, según el artículo 2477 CC, «se pague» a través de la adjudicación.

${ }^{20}$ Figueroa, Juan y Morgado, Erika, Procedimientos civiles e incidentes (Santiago, Thomson Reuters, 2013), p. 356.

${ }^{21}$ Ello podría ser corroborado por la interpretación de alguna doctrina que estima que, aunque el acreedor hipotecario decida ejecutar individualmente el inmueble, de todas formas debe verificar su crédito en el procedimiento concursal. Así, Abeliuk, cit. (n. I7), p. II96. En este contexto, BAEZA, cit. (n. 19), p. 694, entiende que los juicios hipotecarios no están exceptuados de la redefinición de competencia o seudoacumulación de juicios que opera como efecto de la resolución de liquidación, lo que implica que tantos los juicios iniciados, como los nuevos, deben continuar y ser promovidos ante el juez que conoce del concurso. 
Debido a que en esta interpretación son aplicables las normas generales de realización contenidas en el Código de Procedimiento Civil (CPC), la posibilidad de adjudicación del inmueble se produce luego de que el bien no haya podido venderse por primera vez al valor de tasación, o en segunda vez, tras reducirse un tercio el valor de tasación inicial.

En este contexto podría suceder que el valor de adjudicación sea muy inferior al valor de la obligación garantizada, con lo que a pesar de la adjudicación del inmueble por el acreedor, aún existan deudas pendientes tras la pérdida de la vivienda. Ello se debe a que por aplicación de los artículos 485 y ss. CPC, la tasación del inmueble será la que figure en el rol de avalúo fiscal, o en su defecto, aquella efectuada por un perito tasador. En cualquiera de los casos, debido a que los artículos 499 y 500 CPC posibilitan que el bien reduzca su valor hasta los dos tercios del valor inicial de la tasación, o incluso que no tenga un valor mínimo de tasación más que el fijado por el tribunal a efectos del remate, la venta o adjudicación del inmueble del deudor persona natural siempre arrastrará una diferencia en la obligación que no alcanzará a cubrirse con el producto del remate o a través de la adjudicación. ${ }^{22}$

Algunas estadísticas muestran que el ratio de porcentaje de deuda sobre el valor del inmueble (loan to value) en la concesión del crédito se encuentra entre un 70 y $75 \%$ en obligaciones con valor del inmueble de más de I.000 UF, y entre el $5 \mathrm{I}$ y $59 \%$ en obligaciones con valor del inmueble entre 500 y 1.000 UF. ${ }^{23}$ Aunque lo anterior muestra la efectividad de un importante porcentaje de ahorro por parte del contratante del crédito $y$, por tanto, un mayor valor del inmueble en relación con la deuda, como puede apreciarse, son las normas jurídicas aplicables al momento de la liquidación concursal las que conllevan consecuencias desfavorables para el deudor.

En el procedimiento de renegociación, el artículo 266 faculta al acreedor hipotecario a acogerse al acuerdo de renegociación adoptado, o bien, votar en contra del acuerdo, caso en el que su crédito no se considerará en

${ }_{22}$ Resultan interesantes las críticas efectuadas por Contador, Nelson y Palacios, Cristián, Procedimientos concursales (Santiago, Thomson Reuters, 2015), p. 218 y 219, en relación con factores o circunstancias que distorsionan la forma de realización del bien, que se producen en los procedimientos de ejecución de inmuebles a través de la venta al martillo, y que inciden en el valor final del inmueble en el remate, con detrimento a los intereses del deudor. Aunque la ley concursal actual establece la figura del martillero concursal, y aunque la solución planteada por la ley es dar mayor protagonismo a la Junta de Acreedores a la hora de determinar la forma de realización del bien, ello no es óbice para que se mantengan este tipo de artimañas, que afectan el interés del deudor.

${ }^{23}$ Informe Loan to Value Residencial (LTV), cit. (n. 2), p. 9. 
el pasivo y podrá ejecutar la garantía para el pago del crédito. Ello significa que podrá ejecutar la garantía ${ }^{24}$ de manera individual. Si el acreedor opta por la segunda alternativa, la ley no señala expresamente la forma o las reglas a través de las que se llevará a cabo la ejecución del inmueble. Ante la duda, es posible entender que la Ley 20.720 consagra la forma de realización planteada por las normas de prelación de crédito. Si bien el artículo 266 no se refiere a las reglas aplicables, lo anterior es corroborado por el artículo 267 inciso quinto LRLEP, que para el caso de falta de acuerdo en la audiencia de renegociación, hace aplicables las reglas de la prelación de créditos a la ejecución de los activos del deudor en el procedimiento de renegociación. Así las cosas, debido a que por aplicación del artículo 266, la votación en contra del acuerdo de renegociación puede ser entendida como una especie de falta de acuerdo, la ejecución del inmueble hipotecado deberá llevarse a cabo en función de las reglas de prelación de créditos.

Como puede verse, las reglas de prelación de créditos son aplicables a la ejecución en el procedimiento de renegociación cuando no se hubiere logrado acuerdo en la audiencia de renegociación. En este contexto, el artículo 267 inciso quinto señala que el acuerdo de ejecución contendrá «la forma en que serán realizados los bienes de la persona deudora y el pago a los acreedores, en la forma establecida» en el Título XLI del Libro IV del Código Civil sobre la prelación de créditos. Aunque pudiere estimarse que tales normas solo establecen un orden de prelación para el pago, ${ }^{25}$ lo cierto es que, como se ha podido apreciar, respecto del crédito hipotecario establecen reglas concretas de realización del inmueble. Ello explica que el artículo 267 inciso quinto LRLEP se refiera tanto a la «forma en que serán realizados» los bienes, como al "pago de los acreedores», en ambos casos, según las reglas de la prelación de créditos; y que el acreedor hipotecario no está obligado a esperar el resultado de la ejecución, pudiendo ejecutar el inmueble de manera independiente, según los artículos 2477 y 2479 del Código Civil.

En este escenario, se genera en la renegociación el mismo problema interpretativo descrito en el procedimiento de liquidación, respecto de la falta de determinación por parte de la ley concursal de las reglas que en concreto deberán utilizarse para la realización. De ello es que la incertidumbre jurídica del deudor persona natural se mantiene, toda vez que permanece la posibilidad de fijación del valor del inmueble muy por debajo de su valor real.

${ }^{24}$ Así también, Puga, Juan Esteban, Derecho Concursal. El acuerdo de reorganización (Santiago, Editorial Jurídica de Chile, 20I4), p. 47I.

${ }_{25}$ En este sentido parece referirse Puga, cit. (n. 24), p. 475. 
En la fórmula actual, debido a la amplia facultad que tiene el acreedor hipotecario de ejecutar independientemente el inmueble que se constituye en garantía y debido a que le resulta más provechoso escapar al acuerdo de renegociación, preferirá ejecutar individualmente el inmueble, lo que significará la pérdida de la vivienda para el deudor.

\section{El cramdown en el ordenamiento chileno y la pérdida de la vivienda del deudor persona natural}

El Código Civil se pone en el lugar de que el producto de la ejecución del inmueble no alcance para pagar el total de la obligación. Debido a que los artículos 24I y 267 LRLEP aplican todo el título de la prelación de créditos del Código Civil, según el artículo 2490, los créditos preferentes no cubiertos en su totalidad por los medios indicados en los artículos anteriores pasarán por el déficit a la lista de los créditos de la quinta clase, con los que concurrirán a prorrata.

Puesto que gozan de preferencia tanto los créditos privilegiados como la hipoteca, por aplicación de la norma en el procedimiento concursal, en caso de que el producto de la realización del inmueble sea menor al valor de la obligación garantizada, la parte del crédito no cubierto se considerará como crédito de la quinta clase o valista. En este escenario, en la medida que no sean cubiertos los créditos valistas, por aplicación del artículo 28I en relación con el artículo 255, y del artículo 268 inciso segundo, todos de la LRLEP, la parte del crédito no cubierto con el producto de la ejecución de la garantía se extinguirá.

En el derecho comparado, a partir de la constatación de la existencia de hipotecas und ersecured, esto es, casos en que el valor del inmueble que garantiza una obligación (collateral) no es suficiente para cubrir el total del crédito, ${ }^{26}$ se han establecido reglas que permiten modificar el valor de la deuda hipotecaria considerándose el valor de mercado del inmueble.

En el derecho estadounidense, desde el punto de vista teórico, un cramdown constituye una particular forma de alivio a través de la rees-

${ }^{26}$ Whitford, William, Secured creditors and consumer bankruptcy in the United States, en Osgoode Hall Law Journal 37 (1999) I, p. 348; Kaufman, Jane, Lien stripping after nobelman, en Loyola of Los Angeles Law Review 27 (1994) 2, p. 547. Por su parte, NACY, William, Survival underwater: wholly - unsecured security interests in bankruptcy, Washburn Law Journal 40 (2000) I, p. 93, nota al pie 36. De igual forma, Myers, Michael, Dewsnup strikes again: lien-stripping of junior mortgages in chapter 7 and chapter I3, en Arizona Law Review 53 (20II) 4, p. I335, nota al pie 4; LEVITIN, Adam, Resolving the foreclosure crisis: modification of mortgages in bankruptcy, en Wisconsin Law Review (2009) 3, p. 579, nota al pie 39 . 
crituración de un contrato en el que se han establecido ciertas garantías, en oposición o sin el consentimiento de los acreedores — prestamistas o lenders-, con objeto de modificar las fechas de pago, los montos a pagar y las tasas de interés, ${ }^{27}$ en atención al valor de mercado de la propiedad que garantiza el préstamo. ${ }^{28}$

Previa tasación del inmueble, y de acuerdo con la sección 506(a), el tribunal puede dividir o bifurcar un crédito undersecured en dos porciones, una secured, correspondiente a la parte del crédito soportado por el valor del bien hipotecado, y una unsecured, correspondiente a la porción restante ${ }^{29}$; pudiendo evadir o eludir la porción unsecured en virtud de la sección 506(d), que establece que la parte del crédito que no es un secured claim es eludida (void). ${ }^{30}$

A partir de allí, existen dos variantes del cramdown. El strip down conlleva una rebaja del valor de la deuda hipotecaria al valor real o de mercado del bien que garantiza la obligación, previa bifurcación o división del valor del inmueble entre el monto secured y el unsecured..$^{35}$ En teoría, el deudor solo estaría obligado al pago de la parte considerada secured, pudiendo evadir $^{32}$ a través de la descarga de deudas la parte unsecured, tanto en el Capítulo 7 como en el Capítulo 13 del Bankruptcy Code. ${ }^{33}$ Por otro lado, en los casos en que una vivienda es gravada con dos o más hipotecas, el strip off posibilita el descuento o rebaja del monto total de la deuda originada en una o más hipotecas posteriores (junior mortgages) a una primigenia (senior mortgage), cuando el valor real o de mercado de la garantía (collateral) no es suficiente para cubrir el total de los préstamos posterio-

27 Carlson, David, Cars and homes in chapter 13 after the 2005 amendments to the bankruptcy code, en American Bankruptcy Institute Law Review I4 (2006) 2, p. 302 y 303; Kaufman, cit. (n. 26), p. 555

${ }^{28}$ Carlson, David, The chapter 13 estate and its discontents, en American Bankruptcy Institute Law Review 17 (2009) 2, p. 305.

29 Para Whitford, cit. (n. 26), p. 348, la norma establece el principio de bifurcación. Del mismo modo, Levitin, cit. (n. 26), p. 607; NACY, cit. (n. 26), p. 93; HowArd, Margaret, Stripping down liens: section 506(d) and the theory of bankruptcy, en American Bankruptcy Law Journal 65 (1991) 3, p. 375; HowARD, Margaret, Secured claims in bankruptcy: an essay on missing the point, en Capital University Law Review 23 (1994) 2, p. 316.

3o Para un tratamiento de la historia de la sección 506(d), Howard, cit. (n. 29), pp. 375-38I.

${ }^{31}$ Levitin, cit. (n. 26), p. 607.

${ }_{32}$ Nacy, cit. (n. 26), p. 94, nota al pie 43.

33 Whelan, Roger y Cohen, Mandy, Consumer bankruptcy reform: balancing the equities in chapter 13, en American Bankruptcy Institute Law Review 2 (1994) I, p. I8I. 
res, ${ }^{34}$ caso en el que se habla de una wholly unsecured junior mortgage. ${ }^{35}$ Teóricamente, el deudor solo se encontraría obligado al pago de la deuda hipotecaria cubierta con el valor real o de mercado del inmueble (secured debt), pudiendo evadir ${ }^{36}$ a través de la descarga de deudas, la totalidad de obligaciones por créditos hipotecarios posteriores (junior mortgages) no cubiertas por el valor del bien (unsecured debts). ${ }^{37}$

Respecto de ambas formas de rebaja sustancial del monto de la deuda hipotecaria en el concurso, la doctrina se encuentra dividida sobre la posibilidad de aplicación en el Capítulo 7 y Capítulo i3 del Bankruptcy Code. La doctrina a favor argumenta que se trata de una herramienta que beneficia al deudor, puesto que en el procedimiento concursal obtendrá una significativa rebaja de la carga de la deuda total ${ }^{38}$ a través de la evasión legal (avoid) de una parte o la totalidad de una deuda. ${ }^{39}$ En un Capítulo 7 (de liquidación), si bien el deudor perderá el inmueble, podría cubrir el total de la secured debt con el valor real o de mercado obtenido en la realización, pudiendo descargar la parte considerada unsecured debt. En un Capítulo i3 (de plan de pagos aplazado), si se trata de un strip off, facultado para asumir en el período de compromiso el pago del monto equivalente a la secured debt, podría descargar todas las obligaciones hipotecarias posteriores a la primera; mientras que, si se trata de un strip down, optaría a una descarga de la parte de la deuda considerada unsecured, si al final del período del plan hubiere pagado completamente la parte considerada secured.

A diferencia del ordenamiento estadounidense, la Ley de Consumidores francesa (Code de la Consommation) contempla de manera expresa el cramdown, respecto de los créditos titularidad de acreedores garantizados con el inmueble que se constituye en residencia principal de la familia. ${ }^{40}$

${ }^{34}$ Coco, Linda, "Foaming the runway" for homeowners: U.S. Bankruptcy Courts "preserving homeownership" in the wake of the home affordable modification program, en American Bankruptcy Institute Law Review 23 (2015), p. 432.

${ }^{35}$ Myers, cit. (n. 26), p. 1345 .

${ }_{36}$ NACY, cit. (n. 26), p. 94, nota al pie 43.

${ }_{37}$ Myers, cit. (n. 26), p. I335; Whelan y Cohen, cit. (n. 33), p i8i.

${ }^{38}$ Coco, cit. (n. 34), p. 432; Myers, cit. (n. 26), p. I335.

39 NACY, cit. (n. 26), p. 94.

40 Ferriere, Drédérik y Avena-Robardett, Valerie, Surendettement des particuliers (4. ${ }^{\mathrm{a}}$ edición, París, Dalloz, 20I2), p. 247, expresan que la reducción del monto de créditos por venta de inmueble tiene cabida tanto en la venta forzada como en una venta amigable. Kilborn, Jason, La responsabilisation de l'economie: what the United States can learn from the new french law on consumer overindebtedness, en Michigan Journal of International Law 26 (2005) 2, p. 647, se refiere sucintamente a esta norma al señalar: "The court may 
Tanto en su vertiente de strip down, como incluso strip off, el artículo L. 733-4 del Code de la Consommation permite reducir el monto debido a título de préstamo inmobiliario, considerando las circunstancias del deudor, cuando se trata de una venta forzada de la residencia principal del deudor, la obligación emana de un préstamo hipotecario, y el acreedor ha sido satisfecho parcialmente con el producto de la venta del inmueble. ${ }^{4}$

En el ordenamiento nacional, el cramdown consagrado por el artículo 280 en relación con el artículo 24I LRLEP, a su vez en relación con los artículos 2490 del Código Civil, y los artículos 28I, 255 y 268 inciso segundo LRLEP, conlleva el mismo efecto que en el derecho comparado, a saber, la extinción del saldo de la obligación hipotecaria que no hubiere sido cubierta por el producto de la ejecución de la garantía en el procedimiento concursal. En tal escenario, aunque para el deudor es beneficiosa la posibilidad de descargar el monto del crédito que excede el valor de la garantía, de igual manera perderá la vivienda, arrojándolo a él y a su familia a la exclusión social

A diferencia de las posturas teóricas, en nuestro ordenamiento, un strip off o un strip down, no se establecen respecto del procedimiento de renegociación en su vertiente de acuerdo de renegociación. La falta de incentivo para un acuerdo entre el deudor y el acreedor hipotecario, y la facultad de ejecución separada e independiente consagrada en el artículo 266 número 2), implican la pérdida de la oportunidad de que el mismo nivel de cumplimiento de la obligación que sería logrado a través de la ejecución del inmueble, sea obtenido por el acreedor a través de un acuerdo de pagos en un procedimiento de renegociación, pero otorgando la posibilidad de que el deudor conserve el inmueble. Debido a que los saldos insolutos en el procedimiento de renegociación terminado a través de ejecución serán extinguidos por aplicación del artículo 268 inciso segundo, el fomento de un acuerdo entre deudor y acreedor a través del que el valor comercial de la propiedad sea considerado para bifurcar el crédito en una parte cubierta por el valor del inmueble, que deberá cumplir el deudor en un plazo determinado, y otra no cubierta por el valor del inmueble, que será extinguida,

provide for a partial or full discharge only of a deficiency obligation remaining on a home mortgage loan following the forced sale of the home».

${ }_{41}$ Raymond, Guy, Droit de la consommation (París, Lexis Nexis Litec, 2008), p. 338. PaIsant, Gilles, Chroniques. Surendettement de particuliers, en RTD Com. (1996) 4, p. 7 II y Paisant, Gilles, Chroniques. Surendettement de particuliers, en RTD Com. (I998) 2, p. $4 \mathrm{I} 2$, considera que la medida de reducción prevista en la ley puede consistir en la condonación total de la deuda si parece ser la única solución compatible con los recursos y cargas del deudor. 
significa para el acreedor el cumplimiento de la obligación en igual monto que aquel que obtendría a través de la ejecución del inmueble, pero permitiendo al deudor el mantenimiento de la vivienda.

\section{TRATAMIENTO DE LA VIVIENDA EN ORDENAMIENTOS} CONCURSALES COMPARADOS

\section{La vivienda habitual del deudor en el concurso del ordenamiento español}

En el procedimiento concursal español, el acreedor tiene la facultad de ejecutar separadamente el bien inmueble hipotecado. ${ }^{42}$ Por aplicación de los artículos I45, I46 y I49 del Texto Refundido de la Ley Concursal (TRLC), para la procedencia de esta facultad se exige que la vivienda habitual no haya sido considerada como un bien necesario para la continuidad de la actividad profesional o empresarial del deudor.

Respecto del pago de los créditos con privilegio especial (dentro de los que se encuentra el crédito hipotecario), el artículo 430.3 TRLC establece que si no se consigue la completa satisfacción del crédito, la parte no satisfecha será tratada en el concurso con la clasificación que le corresponda. El artículo 497.I.I TRLC expresa que solo serán exonerables los créditos ordinarios y subordinados, mientras que el número I.2 del mismo precepto señala que la parte de los créditos que gozan de privilegio especial que no haya sido satisfecha con la ejecución de la garantía quedará exonerada, salvo que goce de privilegio general. Sobre esta base, entendiendo alguna doctrina que los créditos a los que no se refiere el artículo 497 son «no exonerables» ${ }^{43}$ si una parte del crédito hipotecario goza de privilegio especial o general tras la ejecución, no podría ser exonerado.

El artículo 272 señala que el privilegio especial solo alcanzará la parte del crédito que no exceda el valor razonable de la respectiva garantía y que el importe que exceda del reconocido como privilegio especial será calificado según su naturaleza. ${ }^{44} \mathrm{El}$ cálculo del valor razonable del bien se deter-

${ }^{42}$ Cuena, Matilde, Algunas deficiencias de la Ley Concursal ante la insolvencia de la persona física", en Revista Aranzadi Doctrinal 7 (2009). [visible en: https://eprints.ucm. es/97I4/], p. 8.

${ }^{43}$ Sendra, Álvaro, El beneficio de exoneración del pasivo insatisfecho (Valencia, Tirant lo Blanch, 20I8), p. 215; LATORre, Nuria, El discharge y la propuesta de directiva sobre reestructuración preventiva y segunda oportunidad, en Revista de Derecho Concursal y Paraconcursal 28 (Wolter Kluwer Smarteca), p. 2.

${ }^{44}$ Para Hernández, María del Mar, Los créditos con privilegio, en Campuzano, Ana y SAnjuÁn y Muñoz, Enrique (directores), El derecho de la insolvencia. El concurso de acreedores (3. ${ }^{\mathrm{a}}$ edición, Valencia, Tirant lo Blanch, 2018), pp. 736-748, en ese caso el remanente del crédito pasaría a ser calificado como ordinario. 
minará por un informe emitido por una sociedad de tasación homologada e inscrita en el Registro Especial del Banco de España (artículo 273.I.I), y para la determinación del límite del privilegio especial se descontará del valor razonable el diez por ciento (artículo 275.I.I).

De acuerdo con esto, pudiendo entenderse que el crédito será siempre calificado de privilegio especial en el monto que alcanza el valor razonable de la garantía, en caso de que en la ejecución el monto obtenido sea menor a este valor, la parte no cubierta será privilegio especial en la diferencia entre el importe obtenido por la realización y el valor razonable. En este evento, el monto del crédito más allá del valor de la garantía será calificado según su naturaleza, y podría ser exonerado de acuerdo con el artículo 272.2 en relación con el artículo 497.2, mientras que la diferencia entre el monto obtenido y el valor razonable del bien continuaría siendo crédito con privilegio especial y, por tanto, podría entenderse no exonerable según el artículo $497 .{ }^{45}$

La doctrina está de acuerdo en que el tratamiento de la vivienda habitual en el derecho concursal no significa un beneficio para el deudor, sino que le acarrea consecuencias tan drásticas para él y su familia que es esta otra razón para repudiar la regulación. ${ }^{46}$ Se ha planteado ${ }^{47}$ que la regulación concursal en comento no permite siquiera plantear la posibilidad de exonerar una deuda garantizada y, además, impide valorar la conducta del prestamista a la hora de conceder el préstamo. Vinculado a lo anterior, se ha expresado ${ }^{48}$ que las exigencias al mercado del crédito en torno a la aplicación de medidas en beneficio de los deudores personas físicas han de ser prudentes en materia de créditos con garantía real; salvo en caso de actuación irresponsable del prestamista, no hay razón para imponerle un sacrificio en aquella cuantía de su crédito que esté cubierta por la garantía.

Fuera del ámbito concursal, a través del Real Decreto-Ley 6/20I2, del 9 de marzo, modificado por el RDL I/20I3, de I4 de mayo, de medidas urgentes de protección de deudores hipotecarios y por el RDL I/20I5, de

${ }^{45}$ Dando un ejemplo, Arias, Francisco, Artículo 9o. Créditos con privilegio especial, en Pulgar, Juana (directora), Comentario a la Ley Concursal (Madrid, Wolter Kluwer, 2016), p. II69.

${ }_{46}$ Así lo pone de manifiesto Cuena, Matilde, Mecanismos de protección del patrimonio familiar: inembargabilidad y patrimonio separado", en Revista de Derecho Concursal y Paraconcursal 23 (Wolter Kluwer Smarteca, 2015).

47 Cuena, Matilde, El nuevo régimen de segunda oportunidad. Pocas luces y muchas sombras, en Anuario de Derecho Concursal 37 (2016), p. 49.

${ }^{48}$ Colino, José, Tratamiento de la crisis patrimonial del consumidor: ¿procedimiento colectivo extrajudicial preconcursal, procedimiento colectivo preventivo, o procedimiento concursal especial?, en Cuena, Matilde y Colino, José (coordinadores), Endeudamiento del consumidor e insolvencia familiar (Navarra, Thomson Reuters, 2009), p. 436. 
27 de febrero de mecanismo de segunda oportunidad, y como medida de urgencia frente a las consecuencias de la crisis económica de 2008 , se fomenta la dación en pago en casos de deudores sin recursos. A través de la medida es posible solicitar a los acreedores hipotecarios que se encuentren adheridos al Código de Buenas Prácticas, la dación en pago como medio liberatorio de la deuda, posibilitando que el concursado pueda permanecer en la vivienda durante un plazo de dos años, pagando una renta anual del tres por ciento del importe total de la deuda existente en el momento de la dación. Para ello, el artículo 2 del Real Decreto-Ley exige que el deudor esté situado en el umbral de exclusión.

A pesar de lo esperado, la medida no ha tenido aceptación. Se ha señalado que el requisito vinculado al umbral de exclusión del deudor es muy restrictivo, reservándose solo para casos graves desde el punto de vista socioeconómico, ${ }^{49}$ discriminando a otros que requieren protección pero que no cumplen tales requisitos. ${ }^{50}$ Por otro lado, el límite de valor mínimo de adquisición de la vivienda establecido para la aplicación de la medida limita su impacto de aplicación, sin dejar de mencionar que la medida es aplicable solo en caso de que la institución financiera se haya sometido voluntariamente al Código de Buenas Prácticas. ${ }^{\text {II }}$ Finalmente, dar la vivienda en pago, si bien supone una solución al problema de la deuda, conlleva la pérdida de la misma, pues la propiedad es transferida al acreedor para la cancelación de la deuda. ${ }^{2}$

\section{La homestead exemption en el ordenamiento estadounidense}

En el ordenamiento estadounidense, el U.S. Code establece los bienes de propiedad del deudor que podrán ser exceptuados del activo concursal en la sección 522(d). En virtud de la sección 522(b), los Estados podrán determinar en su derecho estatal sus propias excepciones. ${ }^{53}$ En este escenario, en

49 Alonso, María Teresa, Las diferentes versiones del Código de Buenas Prácticas de reestructuración viable de las deudas con garantía hipotecaria sobre la vivienda habitual, en Tornos, Joaquín y BARral, Immaculada (directores), Vivienda y crisis: ensayando soluciones (Universidad de Barcelona y Registradores de Catalunya, 2015), p. 196.

so Gómez, Carlos, La dació en pagament és la solución?, en Tornos, Joaquín y BARral, Immaculada (directores), Vivienda y crisis: ensayando soluciones (Universidad de Barcelona y Registradores de Catalunya, 20I5), p. 172.

st Anderson, Miriam, ¿Dación en pago o segunda oportunidad?, en Tornos, Joaquín y BARral, Immaculada (dirs.), Vivienda y crisis: ensayando soluciones (Universidad de Barcelona y Registradores de Catalunya, 2015), pp. 158, I63-164.

52 Gómez, cit. (n. 50), p. I70-I7I.

${ }_{53}$ Powers, Brian, Can you trust your trustee? expanding homestead exemptions to include rent-controlled leasehold interests, en American Bankruptcy Institute Law Review 20 (2012) 2, 
el Estado de Texas, reconocido por la doctrina como proteccionista de los intereses del deudor, ${ }^{54}$ tiene sus orígenes la excepción al activo concursal que protege directamente la propiedad que se constituye en residencia principal del deudor o homestead exemption. 55

Una homestead exemption exceptúa bienes específicamente determinados de una venta forzada. ${ }^{56} \mathrm{Su}$ importancia para efectos concursales radica en que el deudor podrá eximir del activo concursal, con escasas limitaciones, la propiedad que se constituye en residencia principal, para aprovecharse de ella sin que los acreedores puedan perseguirla. ${ }^{57}$ Ello posi-

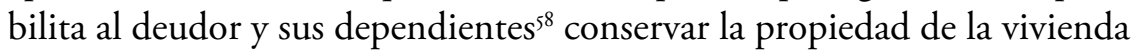
y mantener ciertos bienes que les permitan una mínima calidad de vida y dignidad con posterioridad al procedimiento concursal, 59 minimizando la necesidad de asistencia social y de vivienda pública. ${ }^{60}$

p. 75I; LANDRY, Rober y MARDIS, Nancy, Consumer bankruptcy reform: debtors 'prison without bars or "just desserts» for deadbeats?, en Golden Gate University Law Review 36 (2006) 2, p. 98, nota al pie 46; BLOCH, Amanda, Approaching the limits of the bankruptcy code: does Surcharging a debtor's exempt assets go too far?, en University of Chicago Law Review 76 (2009) 4, p. 1753.

${ }_{54}$ Rushing, Danielle, Use it or lose it: grappling with classification of post-petition sale proceeds under chapter seven bankruptcy for consumer debtors in the lone star state, en St. Mary's Law Journal 49 (2016) 4, p. 903; Kemner, Matthew, Personal bankruptcy discharge and the myth of the unchecked homestead exemption, en Missouri Law Review 56 (1991) 3, p. 685.

s De acuerdo con Resnick, Alan, Prudent planning or fraudulent transfer? the use of nonexempt assets to purchase or improve exempt property on the eve of bankruptcy, en Rutgers Law Review 3I (1978) 4, p. 620; GonZÁLEZ, Henry, The Texas homestead: the last bulwark of liberty, en St. Mary's Law Journal 26 (I995) 2, pp. 339 y 343 y Axelrod, Tristan, Defending state exemption in bankruptcy, en Loyola Consumer Law Review 27 (2015) 2, pp. 294-296, hechos históricos como la depresión sufrida por Estados Unidos en el año I837, la guerra civil y la excesiva hostilidad en zonas rurales de ciertos estados, llevó a que se crearan generosas exenciones, como la homestead exemption.

${ }_{56}$ Boettcher, Charles, Taking Texas home equity for a walk, but keeping it on a short leash!, en Texas Tech Law Review 30 (1999) I, p. 201.

57 Conceptualizando la homestead exemption, Cuena, cit. (n. 46), pp. 2 y ss. Powers, cit. (n. 53), p. 749; Brown, Willian, Political and ethical considerations of exemption limitations: the "opt-out" as child of the first and parent of the second, en American Bankruptcy Law Journal 7I (1997) 2, p. I50; KeMner, cit. (n. 54), p. 685.

${ }^{8}$ BreinsteIn, MacKenzie, The ideal homestead exemption: avoiding asset conversion and fraud but still protecting dependents, en Drake Law Review 58 (2010) 4, p. II26.

59 Resnick, cit. (n. 55), p. 626; Vuкоwich, William, Debtors' exemption rights, en Georgetown Law Journal 62 (1974) 3, pp. 785 y 785; PrICE, Stephen, Florida's homestead exemption: racketeers should not leave home without it, en Stetson Law Review 2I (1992) 2, p. 684, explica que, desde su incorporación, la excepción ha sido arraigada en propósitos humanitarios y socioeconómicos.

60 TARvin, Timothy, Bankruptcy, relocation, and the debtor's dilemma: preserving your 
La regulación de la excepción en Texas presenta, tanto a nivel constitucional como legal, ${ }^{61}$ una protección especial a la propiedad familiar del deudor. El artículo XVI, sección 5o(a) de la Constitución y la sección 42.00I(b)(I) del Property Code establecen que el inmueble residencia principal de una familia o de un adulto soltero es protegida de la venta forzada con propósito de pago a los acreedores, exceptuándose los casos específicamente determinados en la norma ${ }^{62}$ entre los que se encuentran el divorcio, préstamos para mejoras del hogar, préstamos hipotecarios, refinanciamiento de préstamos.

La determinación de la propiedad familiar es relativamente sencilla, permitiendo catalogar como tal una residencia de hasta diez acres si se encuentra en el área urbana, y de hasta doscientos acres si se encuentra en área rural. ${ }^{63}$ Lo anterior posibilita catalogar a la regulación de la excepción entre las más liberales de Estados Unidos, al establecerse la limitación en cuanto a la superficie de la propiedad y no en cuanto a su valor. ${ }^{64} \mathrm{~A}$ ello se agregan reglas procedimentales internas del Estado que impiden la ejecución de una propiedad exenta. ${ }^{65}$ No obstante lo anterior, y a diferencia de la originaria redacción de la disposición constitucional, la norma presenta una visible limitación, puesto que si bien permite exceptuar del concurso una propiedad de ilimitado valor, el derecho no puede ejercerse respecto de una obligación garantizada con hipoteca. ${ }^{66}$

homestead exemption versus accepting the new job out of state, en Loyola University Chicago Law Journal 43 (20II) I, p. I44.

${ }^{6}$ Kemner, cit. (n. 54), p. 686.

${ }^{62}$ Boettcher, cit. (n. 56), p. 202.

${ }_{63}$ Sección 4I.002(a) y (b) Texas Property Code. Rushing, cit. (n. 54), p. 904; BaKer, James L., The Texas homestead exemption's near ban on home equity lending: Its time for the people to decide, en Houston Law Review 33 (1996) I, p. 251.

${ }^{64}$ En esta línea Breinstein, cit. (n. 58), p. II28; BaKer, cit. (n. 63), p. 252.

65 Denham, Michael, A call for bankruptcy reform: the fifth circuit limits the Texas homestead exemption and further complicates the exemption controversy, en Texas Tech Law Review 30 (1999) I, pp. 276, da cuenta de la Tex. Civ. Prac. \& Rem. Code Ann. \$31.002(a), que de acuerdo con su interpretación, incluirían a la propiedad que se constituye en residencia principal en virtud de la homestead exemption. Aunque su postura es minoritaria, para el autor, la interpretación sistemática de las normas que consagran constitucional y estatutariamente la homestead exemption y las normas de procedimiento aludidas, se traducen en que un inmueble que goza del carácter de residencia principal del deudor, que haya sido exento del concurso, no puede ser ejecutado en el procedimiento. En contra, GonZÁlez, cit. (n. 55), p. 339, para quien, aunque la homestead exemption se constituye en una herramienta de protección de la vivienda del deudor, la Constitución de Texas autoriza la ejecución forzada de hipotecas. En esta línea, Breinstein, cit. (n. 58), p. II2I, nota al pie I y p. II3I, nota al pie 42.

${ }^{66}$ Rushing, cit. (n. 54), p. 902. La regulación original de la homestead exemption en 


\section{REFLEXIONES PARA UNA CONSAGRACIÓN DE LA PROTECCIÓN DE LA} VIVIENDA DEL DEUDOR EN EL CONCURSO DEL ORDENAMIENTO NACIONAL

\section{Posibilidad de un obligatorio intento de acuerdo y una facultad} del juez de sustituir la voluntad de los acreedores renuentes

En el ordenamiento alemán, un procedimiento de liquidación judicial o plan de liquidación judicial tiene como objetivo instar el acuerdo entre deudor y acreedor con la ayuda del tribunal. En virtud de la $\$ 309$ de la Insolvenzordnung ( $\mathrm{Ins} \mathrm{O}$ ), el tribunal tiene la autoridad para reemplazar ${ }^{67}$ el consentimiento de los acreedores renuentes a un plan propuesto por el deudor ${ }^{68}$ cuando la mitad de los acreedores concursales hayan aprobado la propuesta efectuada por el deudor y la suma de las reclamaciones de estos acreedores que consienten sea más de la mitad de las reclamaciones de los acreedores concursales.

Si bien la norma señala que el reemplazo no procederá en caso de que la situación del acreedor, con el plan propuesto, sea menos favorable de lo que sería en aplicación de un procedimiento de insolvencia y descarga de la deuda residual (Restschuldbefreiung), y aunque no lo manifiesta expresamente, se aprecia un mecanismo que faculta al juez para intervenir activamente en el logro del acuerdo, debiendo para ello evaluar la adecuación de la propuesta de plan a las circunstancias del caso. Esta misma idea puede verse reflejada en el ordenamiento español, en el que si bien el artículo 496.3 del TRLC no consagra expresamente la posibilidad, es posible interpretar la existencia de una facultad otorgada al juez para reemplazar la voluntad de los acreedores, desde que la norma plantea que el plan propuesto por el deudor será aprobado por el juez en los términos propuestos "o con las modificaciones que estime oportunas».

el Estado de Texas no establecía limitación al deudor para exceptuar de cualquier venta forzada la vivienda familiar, al indicar que "The homestead of a family, or single adult person, shall be, and is hereby protected from forced sale, for the payment of all debts except for the purchase money thereof, or a part of such purchase money, the taxes due thereon, or for work and material used in constructing improvements thereon, and in this last case only when the work and material are contracted for in writing, with the consent of both spouses [...]". Texto en Kemner, cit. (n. 54), p. 686, nota al pie I2.

${ }^{67}$ Lunkenheimer, Cilly y Zimmermann, Dieter, Reformbedarf zur Stärkung der außergerichtlichen Einigung, en ZVI-Zeitschrift für Verbraucher-und Privat-Insolvenzrecht, (2004) 6, p. 3I7.

68 Wiedemann, Rainer, Brauchen wir eine Reform der Verbraucherentschuldung?, en ZVI-Zeitschrift für Verbraucher- und Privat-Insolvenzrecht, (2004) II, p. 649. 
En este contexto, debe notarse que la disposición alemana pone en relieve las circunstancias del acreedor renuente, lo que llevado al ámbito nacional significaría una inoperancia de la norma, desde que la amplia facultad del acreedor para ejecutar individualmente el inmueble —consagrada por la Ley 20.720- siempre le repercutirá mayores beneficios. Así, en caso de que el acreedor hipotecario se acoja al acuerdo propuesto por la Superintendencia de Insolvencia y Reemprendimiento en la audiencia de renegociación, difícilmente podrá lograr la realización del inmueble, por tanto, el pago separado de su acreencia.

Ahora bien, debe destacarse que, en el ordenamiento alemán, las mejores circunstancias del acreedor renuente no se miden en relación con una facultad ilimitada para ejecutar individualmente el inmueble, sino respecto del posible resultado del procedimiento de insolvencia. Así las cosas, en el ámbito nacional, la procedencia de una facultad similar debería ser entendida considerando las eventuales mejores circunstancias que el acreedor renuente podría tener en un procedimiento de liquidación, complementada con un reequilibrio del interés del deudor.

Considerando lo anterior, es criticable que la LRLEP no imponga una obligatoriedad del acuerdo de renegociación al acreedor hipotecario, ${ }^{69} \mathrm{O}$ como mínimo, la obligatoriedad de un intento de acuerdo entre deudor y acreedor en el contexto de un procedimiento de renegociación. ${ }^{70}$ En el entendido de que el objetivo del procedimiento es la reestructuración del pasivo del deudor persona natural a través de modalidades de cumplimiento o modos de extinguir las obligaciones previo acuerdo entre las partes, la obligatoriedad de un intento de acuerdo posibilitaría que al menos se fuerce al acreedor a intentar un acuerdo razonable con su deudor, para evitar la consecuente pérdida de la vivienda. ${ }^{71}$

${ }^{69}$ Por ejemplo, los artículos L 733-I y L 733-3 del Code de la Consommation francés permiten que la Comisión imponga medidas como la reprogramación de créditos, suspensión de exigibilidad de créditos, por más de siete ańos si se trata de créditos hipotecarios sobre la residencia principal del deudor, cuando la situación del deudor no se encuentre irremediablemente comprometida, pero no se haya logrado acuerdo. En virtud del artículo L 733-I6, los acreedores a quienes afecten las medidas, no podrán ejecutar individualmente al deudor.

7o Por ejemplo, la $\$ 305$ InsO, obliga a un intento de acuerdo extrajudicial entre deudor y acreedores previo al concurso, donde tiene injerencia importante una adecuada asesoría de deuda para el deudor. Así, Lunkenheimer y Zimmermann, cit. (n. 67), 317 ss. Sobre las ventajas de una asesoría de deuda social, integral y continua del deudor para fomentar soluciones amigables, Alarcón, Miguel, El concurso de la persona natural. Cuestiones dogmáticas (Valencia, Tirant lo Blanch, 202I), pp. 156 ss. y 173 ss.

${ }^{71}$ Se ha descrito por la doctrina el carácter amigable del procedimiento de renegocia- 
En este contexto, se ha planteado la necesidad de asistencia por parte de los acreedores en el caso de que el deudor se encuentre en dificultades de pago. ${ }^{72} \mathrm{Si}$ bien se manifiesta la necesidad de asistencia en la búsqueda de un acuerdo de renegociación que se ajuste a la realidad de la persona deudora, fundado en las cualidades del acreedor y de su deber de profesionalidad, ello sirve como base para la comprensión de la existencia de un deber de cooperación del acreedor en el procedimiento concursal de renegociación, a partir del cual es posible concebir la pertinencia de una obligación de intento de acuerdo de buena fe beneficioso para el deudor, y en la medida que las circunstancias del caso lo ameriten, sustituir la voluntad del acreedor renuente a una propuesta ajustada a la realidad de la persona deudora.

Ante la pregunta por argumentos que permitan justificar medidas como las señaladas, en el último apartado se avanzan razonamientos.

\section{La exención al activo concursal y sus fundamentos}

Las exenciones al activo concursal son exclusiones de cierta categoría de bienes o activos del deudor, que la ley pone más allá del alcance de los acreedores en el procedimiento concursal, balanceando el conflicto de intereses entre acreedores y deudor. ${ }^{73} \mathrm{La}$ exención proporciona al deudor una cantidad mínima de activos, para que pueda avanzar después del concurso, sirviendo como medida de protección para su persona y familia. ${ }^{74} \mathrm{Al}$ permitirse que el deudor conserve los activos necesarios para su supervivencia económica, las normas de exención del activo concursal cumplen políticas sociales que deben equilibrarse con la necesidad de protección del acreedor. ${ }^{75}$

En el ordenamiento nacional, por aplicación de los artículos 271 y 276 LRLEP, las excenciones al activo concursal son los bienes inembargables a los que se refiere el artículo 445 CPC. En aplicación del número 8 de la norma, el único bien raíz inembargable es el que el deudor ocupa con

ción, desde la comprensión de que las partes deben tener la disposición para buscar una solución que beneficie a todos. Así, Goldenberg, Juan Luis, El crédito por intereses en el marco de los procedimientos concursales, en Revista de Derecho (Universidad Católica del Norte) 25 (2018) 2, p. 164 y Contador y Palacios, cit. (n. 22), p. 243.

${ }_{72}$ Goldenberg, cit. (n. II), p. 20, en el marco de los deberes que emanan del «deber de profesionalidad» del concedente del crédito.

73 Kemner, cit. (n. 54), p. 683.

${ }^{74}$ LANDRY, Rober, Ethical considerations in filing personal bankruptcy: a hypothetical case study, en Journal of Legal Studies Education 29 (2012) I, p. 68, nota al pie 56. Así también, Lombino, Richard, Uniformity of exemptions: assessing the commission's proposals, en American Bankruptcy Institute Law Review 6 (1998) I, p. I77.

75 Resnick, cit. (n. 55), p. 615. 
su familia, siempre que no tenga un avalúo fiscal superior a cincuenta unidades tributarias mensuales o se trate de una vivienda de emergencia, y sus ampliaciones, a que se refiere el artículo 5 del Decreto Ley 2.552, de 1979. Quedan fuera, por tanto, los bienes inmuebles adquiridos a través de crédito hipotecario.

Las exenciones al activo concursal se fundamentan en la necesidad de proveer a los deudores y sus familias de un mínimo de bienes o ingresos que permitan enfrentar la vida después del concurso de manera digna. ${ }^{76}$ Considerando que las exenciones al activo concursal — junto a la descarga- son una especial herramienta para lograr el objetivo de otorgar un efectivo alivio al deudor, ${ }^{77}$ su justificación se encuentra en el reconocimiento por parte de la legislación de la inherente dignidad de cualquier ser humano, para serle otorgada una oportunidad para vivir en condiciones económicas básicas que respondan a tal dignidad y permita ponerle en el camino de la autodeterminación como miembro que contribuye a la existencia de la sociedad y la protección de sus dependientes. ${ }^{78}$

\section{El significado de la vivienda del deudor y su vinculación} con la finalidad del procedimiento concursal de persona natural

Partiendo de la primacía de los intereses de los acreedores garantizados en el procedimiento concursal, se ha señalado que la protección de los deudores personas naturales debe limitarse a lo estrictamente necesario para evitar la exclusión social, lo que permitiría comprender como razonable la exigencia al deudor de buena fe y a su familia de un suficiente grado de austeridad en su vida, para equilibrar sacrificios. ${ }^{79}$

Sin embargo, en atención a la naturaleza y especiales circunstancias del deudor persona natural, requiere de un nivel de protección para el

${ }^{76}$ LANdry, cit. (n. 74), p. 68, nota al pie 56; Lombino, cit. (n. 74), p. I77; Bloch, cit. (n. 53), p.I753; LANDRY y MARDIs, cit. (n. 53), p. 97, nota al pie 43.

77 Kemner, cit. (n. 54), pp. 684 y 685.

${ }^{78}$ FLINT, Richard, Bankruptcy Policy: toward a moral justification for financial rehabilitation of the consumer debtor, en Washington and Lee Law Review 48 (I99I) 2, p. 536; TABB, Charles, The scope of the fresh start in bankruptcy: collateral conversions and the dischargeability debate, en George Washington Law Review 59 (1990) I, p. 95. Brown, cit. (n. 57), p. I69 y ReSNick, cit. (n. 55), pp. 62I, expresan que el propósito detrás de las exenciones al activo concursal es proporcionar al deudor que lo merece los bienes necesarios para su subsistencia, protección de la dignidad e identidad cultural y religiosa, la rehabilitación financiera y capacidad de obtener ingresos futuros y la protección de la familia del deudor de las adversas consecuencias del empobrecimiento.

79 Colino, cit. (n. 48 ), p. 436. 
cumplimiento del objetivo de alivio, ${ }^{80} \mathrm{o}$, en otras palabras, el logro de la erradicación del riesgo de exclusión social en su persona y familia. ${ }^{81}$ Aunque sería necesario efectuar una identificación de los intereses y razones presentes en los derechos fundamentales en colisión, puede estimarse a priori que un adecuado entendimiento de la finalidad del procedimiento concursal de persona natural, esto es, la solución real o efectiva del problema subyacente a la insolvencia del deudor ${ }^{82}$ implica el entendimiento de que ciertos bienes deben ser excluidos del activo concursal para escapar de la acción de los acreedores, teniendo en consideración la especial naturaleza y función que detentan para un individuo en particular y en atención a las necesidades de la familia. ${ }^{8_{3}}$

Desde una dimensión social, la vivienda es el espacio donde el individuo encuentra protección, tiene control y le otorga un sentido de liber$\operatorname{tad}^{84}$; un espacio en el que la familia convive para satisfacer sus necesidades básicas, que caracteriza las condiciones materiales de la vida familiar y un bien de primera necesidad, que influye en la realización de las funciones familiares, la estabilidad, el equilibrio emocional, el estado de salud y capacidad de trabajo de sus moradores: ${ }^{85}$ "Es algo más que un techo, es un espacio integrador de procesos sociales necesario para la consolidación de la familia y el desarrollo de sus miembros». ${ }^{86}$

80 Sobre el particular, Alarcón, cit. (n. 70), pp. 52 ss. y I4I ss.

${ }^{81}$ Manifestando el riesgo de exclusión social en caso de pérdida de la vivienda, Alonso, cit. (n. 49), p. I94.

${ }_{22}$ Así, Alarcón, Miguel, El principio del fresh start como exigencia normativa derivada de la dignidad humana, en Doxa. Cuadernos de Filosofía del Derecho 44 (202I), p. 319; Alarcón, cit. (n. 70), pp. 52 ss. Goldenberg, cit. (n. II), p. 20, lo plantea vinculado al ámbito económico del deudor; y en relación con el sobreendeudamiento, antesala de la insolvencia, Caballero, Guillermo, Sobreendeudamiento y exoneración legal de los saldos insolutos en el procedimiento concursal del consumidor, en Ius et Praxis 24 (2018) 3, p. I39, lo vincula con la imposibilidad de desarrollar una vida normal en atención a la falta de medios materiales, y con elementos psicológicos de aflicción al contemplar las dificultades personales del deudor.

${ }^{83}$ Esta especial funcionalidad también es apreciada por Cuena, cit. (n. 46), p. I.

${ }^{84}$ Sebba, Rachel y Churchman, Arza, The Uniqueness of the Home, en Architecture and Behaviour 3 (1986) I, p. 9.

85 Conceptualizando a la vivienda, destacando su valor como estructura física, que ofrece refugio material; como territorio, que ofrece seguridad, control, permanencia, privacidad; como centro de la propia identidad, que proporciona autonomía, ofrece un reflejo de las propias ideas, valores y aspiraciones, y actúa como indicador del estado personal; y como unidad social y cultural, que actúa como lugar para las relaciones con la familia, amigos y centro de actividades, Fox, cit. (n. I5), pp. 590 ss., especialmente pp. 592, 596, 598-599.

${ }^{86}$ Gazmuri, Patricia, Familia y habitabilidad en la vivienda. Aproximaciones metodoló- 
Bajo esta perspectiva, hablamos de una exención al activo del concurso de un bien que, primero, se constituye efectivamente en vivienda, y luego, en ciertos casos, se constituye en el único medio a través del cual el deudor mantiene circunstancias de vida mínimas que garantizan el mantenimiento de la capacidad de desarrollar libremente su personalidad, y con el cual mantener la estabilidad y protección de la familia. ${ }^{87}$

Se ha señalado que el significado social y humano que tiene la pérdida de la vivienda familiar de una persona endeudada invita a reflexionar acerca de la posible moderación o exclusión de esta penosa pérdida. ${ }^{88} \mathrm{El}$ reconocimiento de la dimensión social de la vivienda del deudor implica reconocer la necesidad de equilibrar el interés comercial en la propiedad como capital o activo de inversión, con el interés del deudor, de su familia y el valor que la vivienda representa para el individuo o conjunto de individuos que la habitan. ${ }^{89}$ En este contexto, la exclusión del activo concursal de la vivienda del deudor en situación de vulnerabilidad, significa para él y su familia la concreción de eficientes, estables o seguros modos y medios de desarrollo de su existencia y de su entorno familiar, ${ }^{9 \circ}$ que le permiten una calidad de vida ${ }^{91}$ o estado de cosas conformado por un conjunto de aspectos o capacidades de hacer, ser y operar individual y colectivamente

gicas para su estudio desde una perspectiva sociológica, en Arquitectura y Urbanismo 34 (2013) I, p. 33. En este sentido, Sebba y Churchman, cit. (n. 84), p. 9, destacan la libertad de comportamiento que el hogar brinda a la familia, que permite la crianza de los hijos de acuerdo con los propios valores, y que cada miembro actúe con naturalidad y exprese sus emociones entre sí.

${ }^{87}$ En este sentido, sobre las justificaciones de la homestead exemption, RESNICK, cit. (n. 55), p. 622.

${ }^{88}$ Así, Blanquer, Roberto, La vivienda familiar (endeudamiento del consumidor e insolvencia familiar, en Cuena, Matilde y Colino, José (coordinadores), Endeudamiento del consumidor e insolvencia familiar (Navarra, Thomson Reuters, 2009), p. 313. Del mismo modo, aunque refiriéndose a la paralización de la ejecución hipotecaria en el concurso, Jiménez, Teresa, Vivienda familiar y concurso de acreedores, en Cuena, Matilde (coordinadora), Familia y concurso de acreedores (Navarra, Thomson Reuters, 20IO), p. 28I.

${ }_{89}$ El choque entre los intereses económicos, vinculados a los acreedores, y los intereses económicos o no económicos que presentan los ocupantes de la vivienda, es manifestado por Fox, cit. (n. I5), p. 583 y 608.

${ }^{\circ}$ De acuerdo con Kemner, cit. (n. 54), p. 686, los propósitos detrás de la instauración de la homestead exemption fueron preservar la integridad de la familia, evitar que deudores agobien a la sociedad e inculcar sentimiento de independencia y estabilidad en los ciudadanos. En el mismo sentido Boettcher, cit. (n. 56), p. 204.

91 García, Emilio, Derechos humanos y calidad de vida, en González, Graciano, Derechos humanos. La condición humana en la sociedad tecnológica (Madrid, Tecnos, 1999), p. I48. 
en un espacio y tiempo social determinados, ${ }^{92}$ que le permiten el libre desarrollo de su personalidad y el desarrollo de su familia, concordantes con el respecto y fomento de la dignidad. ${ }^{93}$

En el derecho comparado, respecto de la exención al activo concursal de los alimentos otorgados al deudor y su familia durante el procedimiento, se ha manifestado ${ }^{94}$ que es la necesidad la que permite atemperar el rigor del artículo ı9ıı del Código Civil español —en nuestro ordenamiento, artículo 2465 del Código Civil_- y aplicar bienes del concurso a la satisfacción de las necesidades del deudor y su familia, sin saldar íntegramente los créditos. ${ }^{95}$ Por otro lado, se ha expresado que esta necesidad existirá cuando los bienes inembargables no sean suficientes para asegurar la vida digna del concursado y su familia. ${ }^{96}$

En este punto, surge la duda respecto de cuál sería el criterio adecuado para definir en qué casos aplicar la exclusión. Ello no es un tema menor, debido a que criterios automáticos de delimitación significarían un límite para ciertos deudores que, no cumpliendo tales requisitos, aun así requerirían de protección. Ello sucede en el ordenamiento español, que establece requisitos rígidos para comprender que una persona se encuentra en el umbral de la exclusión para aplicar una dación en pago; en el ordenamiento estadounidense, que para la aplicación de la homestead exemption

92 Sobre las capacidades como elemento que define la calidad de vida, García, cit. (n. 9I), p. I48, plantea aspectos materiales, psicológicos y socioculturales; STIGLITZ, Joseph, Sen, Amartya y Fitoussi, Jean-Paul, Report by the Commission on the Measurement of Economic Performance and Social Progress (2009) [visible en: https://bit.ly/3zL6k3Y], pp. 42-44, I43 ss., y 216; STiglitz, Joseph E., Sen, Amartya y Fitoussi, Jean-Paul, Informe de la comisión sobre la medición del desarrollo económico y del progreso social (2009) [visible en: https://bit.ly/3h2Hmpx], p. I3. JimÉnez, Wilson y GonzÁLEz, Jorge, Calidad de vida urbana: una propuesta para su evaluación, en Revista de Estudios Sociales 9 (2014), p. I64, expresan que «la calidad de vida se puede entender como la satisfacción derivada de las posibilidades de desarrollar autónomamente su proyecto vital».

${ }_{93}$ Realzando la importancia de la vivienda habitual para la persona, reflejado en el derecho a la vivienda digna y adecuada, Alonso, cit. (n. 49), p. I94. Sobre el enfoque de las capacidades de Amartya Sen y su vinculación con la dignidad, Martínez, Pablo, El "enfoque de las capacidades» de Martha Nussbaum frente el problema de la ética animal, en Veritas (2015) 33, pp. 74 y 75.

94 Duro Ventura, C., Artículo 47, en Palomar, A. (coordinador), Comentarios a la legislación concursal (Madrid, Dykinson), p. 512.

${ }_{95}$ En nuestro ordenamiento, Bozzo, cit. (n. I2), p. 166, ha señalado la necesidad de atenuar principios como el de fuerza obligatoria de los contratos y el de prenda general de los acreedores.

96 Nanclares, Javier, Artículo 47, en Cordón, Faustino (director), Comentarios a la Ley Concursal (Pamplona, Aranzadi, 2004), p. 380. 
considera el valor de la propiedad; o en el derecho chileno, que establece como bien inembargable a la vivienda de protección o de características que implican su aplicación a casos de extrema necesidad. Por otro lado, una consideración amplia de la exclusión conllevaría abrir la posibilidad de abuso del procedimiento por parte del deudor, y una restricción injustificada de las posibilidades de pago de los acreedores, ${ }^{97}$ lo que podría incidir negativamente en el aumento del costo y acceso al crédito. A partir de la finalidad de la regulación concursal de la persona natural, ambas circunstancias deben también limitarse.

Desde este punto de vista, el inmueble que se constituye en vivienda familiar u hogar del deudor debiere ser excluido del activo concursal cuando las circunstancias de vida particulares del deudor signifiquen una situación de necesidad tal que repercuta en riesgo de exclusión social o, como entendemos, falta de desarrollo personal y familiar. Como criterio no automático, requiere de la valoración de todas y cada una de las circunstancias del deudor, y que más allá del ámbito meramente económico, representarán los condicionantes que para cada caso particular permitirán o no que la pérdida de la vivienda habitual del deudor en el concurso conlleve la externalidad negativa de imposición o generación de precarias condiciones de vida, a saber, deficientes, inestables o inseguros modos o medios de desarrollo de su existencia y de su entorno familiar, que le privan de una calidad de vida o estado conformado por un conjunto de aspectos o capacidades de hacer, ser y operar individual y colectivamente en un espacio y tiempo social determinados.

Para lograr lo anterior, comprendiendo y valorando en qué casos nos encontraremos frente a deudores que habrían de ser beneficiados con una medida como la propuesta, y para equilibrar los intereses de las partes en el procedimiento concursal, la cuestión pasa por la necesidad de establecimiento de mecanismos concursales que, comprendiendo las necesidades de los diversos tipos de deudores en el concurso, permitan apreciar de manera efectiva la situación patrimonial del deudor en función de todas y cada una de sus circunstancias de vida..$^{98}$ De igual forma, y aunque se ha constatado que la mayoría de los deudores que ingresan al procedimiento

${ }_{97}$ Aunque la idea no pasa por predefinir una inembargabilidad, sino apreciar los casos concretos en el concurso, se puede colegir tal consecuencia de lo señalado por FERNÁNDEZ, Clara, Umbrales de inembargabilidad, en Cuena, Matilde (directora), La prevención del sobreendeudamiento privado. Hacia un préstamo y consumo responsables (Navarra, Aranzadi, 20I7), p. 713. En todo caso, la autora plantea como positiva la consecuencia de contribuir a una concesión responsable de crédito.

${ }_{98}$ Considerando algunas propuestas, Alarcón, cit. (n. 70), pp. I22 ss., I 56 ss. y I73 ss. 
concursal lo hacen víctimas de circunstancias imprevisibles, ${ }^{99}$ se requiere de un adecuado mecanismo de acceso del deudor a los beneficios que proporciona la ley concursal en atención a la conducta llevada a cabo para con sus acreedores durante la contratación y con posterioridad a la misma. ${ }^{100}$

\section{Conclusiones}

La desprotección de la vivienda del deudor persona natural por el ordenamiento concursal impone consecuencias negativas para las aspiraciones de desarrollo personal del deudor y su familia.

La falta de incentivos por parte del ordenamiento concursal para el mantenimiento de la vivienda del deudor, en un procedimiento de liquidación o en uno de renegociación, repercute en la comprensión de la existencia de un desequilibrado nivel de protección de los intereses en favor de los acreedores.

Si bien a nivel comparado no se constata una protección especial para la vivienda del deudor persona natural, la vinculación del significado de la misma con la finalidad del procedimiento concursal de persona natural implica la necesidad de reequilibrar los intereses en el concurso, para construir un conjunto de herramientas que permitan la protección de la vivienda del deudor por el procedimiento que se concreta como la última oportunidad para que el deudor obtenga una solución definitiva al problema de la insolvencia.

\section{Bibliografía}

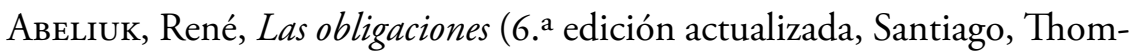
son Reuters, 20I4), II.

Alarcón, Miguel, La deuda por obligación constituida a través de crédito con aval del estado no constituye excepción al discharge en el ordenamiento jurídico chileno, en Revista Chilena de Derecho Privado 3I (2018).

Alarcón, Miguel, El principio del fresh start como exigencia normativa

99 Stephan, Guido, Stellungnahme zum Referentenentwurf eines Gesetzes zur Verkürzung des Restschuldbefreiungsverfahrens, zur Stärkung der Gläubigerrechte und zur Insolvenzfestigkeit von Lizenzen, en Zeitschrift für Verbraucher- und Privat-Insolvenzrecht (2012) 3, p. 86; Alarcón, cit. (n. I2), p. I7; Caballero, cit. (n. 82) 3, p. I37. Considerando estadísticas para el ámbito nacional, en caso de sobreendeudamiento pasivo, GoldenberG, cit. (n. II), pp. 3 y II; Ruz, cit. (n. I2), pp. 487 y 488.

roo Sobre el punto de la buena fe del deudor, Alarcón, cit. (n. 70), pp. 315 ss.; CabaLLERO, cit. (n. 82), pp. I62 y I65 ss. 
derivada de la dignidad humana, en Doxa. Cuadernos de Filosofia del Derecho 44 (202I).

Alarcón, Miguel, El concurso de la persona natural. Cuestiones dogmáticas (Valencia, Tirant lo Blanch, 202I).

Alarcón, Miguel, El deber de evaluación de la solvencia del deudor persona natural por el prestamista y su necesaria implementación en el ordenamiento jurídico chileno. Propuesta interpretativa para su reconocimiento, en Isler, Erika (directora), GPS de Derecho de Consumo (Valencia, Tirant lo Blanch, 202I), en prensa.

Alonso, María Teresa, Las diferentes versiones del Código de Buenas Prácticas de reestructuración viable de las deudas con garantía hipotecaria sobre la vivienda habitual, en Tornos, Joaquín y BARRAL, Immaculada (directores), Vivienda y crisis: ensayando soluciones (Universidad de Barcelona y Registradores de Catalunya, 2015).

Anderson, Miriam, ¿Dación en pago o segunda oportunidad?, en Tornos, Joaquín y BARRAL, Immaculada (directores), Vivienda y crisis: ensayando soluciones (Universidad de Barcelona y Registradores de Catalunya, 20I5).

Arias, Francisco, Artículo 9o. Créditos con privilegio especial, en Pulgar, Juana (directora), Comentario a la Ley Concursal (Madrid, Wolter Kluwer, 20I6).

Axelrod, Tristan, Defending state exemption in bankruptcy, en Loyola Consumer Law Review 27 (2015) 2.

BAEzA, Gonzalo, Derecho concursal chileno. Legislación vigente y reforma proyectada (Santiago, Thomson Reuters, 20I3), I.

BAKer, James L., The Texas homestead exemption's near ban on home equity lending: Its time for the people to decide, en Houston Law Review 33 (1996) I.

Boletín Estadístico Mensual, diciembre 2019 y diciembre 2020, Superintendencia de Insolvencia y Reemprendimiento. [visible en: https://bit.ly/3jFwkYX y https://bit.ly/3hoKwtY]

BlANQUer, Roberto, La vivienda familiar (endeudamiento del consumidor e insolvencia familiar, en Cuena, Matilde y Colino, José (coordinadores), Endeudamiento del consumidor e insolvencia familiar (Navarra, Thomson Reuters, 2009).

Bloch, Amanda, Approaching the limits of the bankruptcy code: does Surcharging a debtor's exempt assets go too far?, en University of Chicago Law Review 76 (2009) 4.

BoetTCHer, Charles, Taking Texas home equity for a walk, but keeping it on a short leash!, en Texas Tech Law Review 30 (1999) I. 
Bozzo, Sebastián, Sobreendeudamiento del consumidor en Chile: una revisión a la luz del derecho europeo, en Revista de Derecho (Valdivia) 33 (2020) I.

Breinstein, MacKenzie, The ideal homestead exemption: avoiding asset conversion and fraud but still protecting dependents, en Drake Law Review 58 (2010) 4.

Brown, Willian, Political and ethical considerations of exemption limitations: the "opt-out» as child of the first and parent of the second, en American Bankruptcy Law Journal 7I (1997) 2.

Caballero, Guillermo, Sobreendeudamiento y exoneración legal de los saldos insolutos en el procedimiento concursal del consumidor, en Ius et Praxis 24 (2018) 3.

Carlson, David, Cars and homes in chapter 13 after the 2005 amendments to the bankruptcy code, en American Bankruptcy Institute Law Review I4 (2006) 2.

Carlson, David, The chapter 13 estate and its discontents, en American Bankruptcy Institute Law Review 17 (2009) 2.

Coco, Linda, "Foaming the runway" for homeowners: U.S. Bankruptcy Courts "preserving homeownership" in the wake of the home affordable modification program, en American Bankruptcy Institute Law Review 23 (20I5).

Colino, José, Tratamiento de la crisis patrimonial del consumidor: ¿procedimiento colectivo extrajudicial preconcursal, procedimiento colectivo preventivo, o procedimiento concursal especial?, en Cuena, Matilde y ColiNo, José (coordinadores), Endeudamiento del consumidor e insolvencia familiar (Navarra, Thomson Reuters, 2009).

Contador, Nelson y Palacios, Cristián, Procedimientos concursales (Santiago, Thomson Reuters, 20I5).

Cuena, Matilde, Algunas deficiencias de la Ley Concursal ante la insolvencia de la persona física», en Revista Aranzadi Doctrinal 7 (2009). [visible en: https://eprints.ucm.es/97i4/]

Cuena, Matilde, Mecanismos de protección del patrimonio familiar: inembargabilidad y patrimonio separado", en Revista de Derecho Concursal y Paraconcursal 23 (Wolter Kluwer Smarteca, 2015).

Cuena, Matilde, El nuevo régimen de segunda oportunidad. Pocas luces y muchas sombras, en Anuario de Derecho Concursal 37 (2016).

Cuentas Nacionales de Chile (2020), [visible en: https://bit.ly/3yOhK64]

Cuentas Nacionales por Sector Institucional, Banco Central de Chile (2019) [visible en: https://bit.ly/3DKoyoR] 
Cuentas Nacionales por Sector Institucional, Segundo trimesTRE, Banco Central de Chile (2020) [visible en: https://bit.ly/38Bp$\mathrm{VYy}]$

Denham, Michael, A call for bankruptcy reform: the fifth circuit limits the texas homestead exemption and further complicates the exemption controversy, en Texas Tech Law Review 30 (I999) I.

Denegri, Marianela, Cabezas, Daniel, del Valle, Carlos, González, Yéssica y Sepúlveda, Jocelyne, Escala de actitudes hacia el endeudamiento: validez factorial y perfiles actitudinales en estudiantes universitarios chilenos, en Universitas Psychologica. Panamerican Journal of Psychology II (2OI2) 2.

Duro Ventura, C., Artículo 47, en Palomar, A. (coordinador), Comentarios a la legislación concursal (Madrid, Dykinson).

Encuesta Financiera de Hogares 20I7, Banco Central de Chile (20I8) [visible en: https://www.efhweb.cl/]

Equipo de Investigación Facultad de Psicología de la Universidad de Granada y Escuela Andaluza de Salud Pública, Estado de salud de la población afectada por un proceso de desahucio (20I4) [visible en: https://bit.ly/3zJAuos]

Fernández, Clara, Umbrales de inembargabilidad, en Cuena, Matilde (directora), La prevención del sobreendeudamiento privado. Hacia un préstamo y consumo responsables (Navarra, Aranzadi, 20I7).

Ferriere, Drédérik y Avena-Robardett, Valerie, Surendettement des particuliers $\left(4 \cdot{ }^{\mathrm{a}}\right.$ edición, París, Dalloz, 20I2).

Figueroa, Juan y Morgado, Erika, Procedimientos civiles e incidentes (Santiago, Thomson Reuters, 2013).

FLINT, Richard, Bankruptcy Policy: toward a moral justification for financial rehabilitation of the consumer debtor, en Washington and Lee Law Review 48 (I99I) 2.

Fox, Lorna, The meaning of home: a chimerical concept or a legal challenge?, en Journal of Law and Society 29 (2002) 4.

García, Emilio, Derechos humanos y calidad de vida, en GonzÁlez, Graciano, Derechos humanos. La condición humana en la sociedad tecnológica (Madrid, Tecnos, I999).

Gazmuri, Patricia, Familia y habitabilidad en la vivienda. Aproximaciones metodológicas para su estudio desde una perspectiva sociológica, en Arquitectura y Urbanismo 34 (2013) I.

Goldenberg, Juan Luis, El necesario ajuste de la asignación del riesgo de sobreendeudamiento en la regulación de las tarjetas de crédito: desde un sistema basado en los deberes de información a un modelo de corresponsa- 
bilidad, en Revista de Derecho (Pontificia Universidad Católica de Valparaiso) 49 (2017) 2.

Goldenberg, Juan Luis, El crédito por intereses en el marco de los procedimientos concursales, en Revista de Derecho (Universidad Católica del Norte) 25 (2018) 2.

GoldenberG, Juan Luis, El sobreendeudamiento y los paradigmas del consumidor financiero responsable y del proveedor financiero profesional, en Ius et Praxis 26 (2020) I.

GonzÁlez, Henry, The Texas homestead: the last bulwark of liberty, en St. Mary's Law Journal 26 (1995) 2.

GonzÁlez, Felipe, Crédito, deuda y gubernamentalidad financiera en Chile, en Revista Mexicana de Sociología 80 (2018) 4.

Gómez, Carlos, La dació en pagament és la solución?, en Tornos, Joaquín y BARRAL, Immaculada (directores), Vivienda y crisis: ensayando soluciones (Universidad de Barcelona y Registradores de Catalunya, 2015).

Hernández, María del Mar, Los créditos con privilegio, en Campuzano, Ana y Sanjuán y Muñoz, Enrique (directores), El derecho de la insolvencia. El concurso de acreedores ( $3 \cdot^{\text {a }}$ edición, Valencia, Tirant lo Blanch, 20I8).

HowARD, Margaret, Stripping down liens: section $506(d)$ and the theory of bankruptcy, en American Bankruptcy Law Journal 65 (I99I) 3.

Howard, Margaret, Secured claims in bankruptcy: an essay on missing the point, en Capital University Law Review 23 (1994) 2.

Informe de Endeudamiento, Superintendencia de Bancos e Instituciones Financieras (2018) [visible en: https://bit.ly/3DUWrDA]

Informe de Endeudamiento, Comisión para el Mercado Financiero (2019) [visible en: https://bit.ly/2WPGnlC]

Informe de Endeudamiento, Comisión para el Mercado Financiero (2020) [visible en: https://bit.ly/3DLanzN]

Informe Endeudamiento Nacional, Consultora Bio Bio Sur (20I5) [visible en: https://bit.ly/2YjxxNn]

Informe Loan to Value Residencial (LTV): Estadísticas en Series DE Tiempo, Superintendencia de Bancos e Instituciones Financiera (20I9) [visible en: https://bit.ly/3DGpHhj]

JimÉnez, Magdalena, Aproximación teórica de la exclusión social: complejidad e imprecisión del término. Consecuencias para el ámbito educativo, en Estudios Pedagógicos 34 (2008) I.

Jiménez, Teresa, Vivienda familiar y concurso de acreedores, en Cuena, Matilde (coordinadora), Familia y concurso de acreedores (Navarra, Thomson Reuters, 20I0). 
Jiménez, Wilson y González, Jorge, Calidad de vida urbana: una propuesta para su evaluación, en Revista de Estudios Sociales 9 (2014).

Kaufman, Jane, Lien stripping after nobelman, en Loyola of Los Angeles Law Review 27 (1994) 2.

Kemner, Matthew, Personal bankruptcy discharge and the myth of the unchecked homestead exemption, en Missouri Law Review 56 (I99I) 3.

Kilborn, Jason, La responsabilisation de l'economie: what the United States can learn from the new french law on consumer overindebtedness, en $\mathrm{Mi}$ chigan Journal of International Law 26 (2005) 2.

LANDRY, Rober, Ethical considerations in filing personal bankruptcy: a hypothetical case study, en Journal of Legal Studies Education 29 (20I2) I.

LANDRY, Rober y MARDIS, Nancy, Consumer bankruptcy reform: debtors' prison without bars or "just desserts" for deadbeats?, en Golden Gate University Law Review 36 (2006) 2.

LATORRe, Nuria, El discharge y la propuesta de directiva sobre reestructuración preventiva y segunda oportunidad, en Revista de Derecho Concursal y Paraconcursal 28 (Wolter Kluwer Smarteca).

LEVITIN, Adam, Resolving the foreclosure crisis: modification of mortgages in bankruptcy, en Wisconsin Law Review (2009) 3.

Lombino, Richard, Uniformity of exemptions: assessing the commission's proposals, en American Bankruptcy Institute Law Review 6 (I998) I.

Lunkenheimer, Cilly y Zimmermann, Dieter, Reformbedarf zur Stärkung der außergerichtlichen Einigung, en ZVI-Zeitschrift für Verbraucher-und Privat-Insolvenzrecht (2004) 6.

Marambio, Alejandro, Endeudamiento "saludable», empoderamiento y control social, en Polis. Revista Latinoamericana (2018) 42.

Martínez, Pablo, El "enfoque de las capacidades» de Martha Nussbaum frente el problema de la ética animal, en Veritas (2015) 33.

Myers, Michael, Dewsnup strikes again: lien-stripping of junior mortgages in chapter 7 and chapter I3, en Arizona Law Review 53 (20II) 4.

NACY, William, Survival underwater: wholly - unsecured security interests in bankruptcy, Washburn Law Journal 40 (2000) I.

Nanclares, Javier, Artículo 47, en Cordón, Faustino (director), Comentarios a la Ley Concursal (Pamplona, Aranzadi, 2004).

PaIsant, Gilles, Chroniques. Surendettement de particuliers, en RTD Com. (I996) 4 .

PaIsant, Gilles, Chroniques. Surendettement de particuliers, en RTD Com. (I998) 2.

PÉRez-RoA, Lorena y Gómez, Matías, Deuda, temporalidad y moralidad: Proceso de subjetivación de parejas jóvenes profesionales, en Psicoperspectivas I8 (2019) 3 . 
Pevalian, D. J., Housing repossessions, evictions and common mental illness in the UK: results from a household panel study, en J Epidemiol Community Health 63 (2009).

Powers, Brian, Can you trust your trustee? expanding homestead exemptions to include rent-controlled leasehold interests, en American Bankruptcy Institute Law Review 20 (2012) 2.

PRICE, Stephen, Florida's homestead exemption: racketeers should not leave home without it, en Stetson Law Review 2I (1992) 2.

PugA, Juan Esteban, Derecho Concursal. El acuerdo de reorganización (Santiago, Editorial Jurídica de Chile, 20I4).

Raymond, Guy, Droit de la consommation (París, Lexis Nexis Litec, 2008).

RESNICK, Alan, Prudent planning or fraudulent transfer? the use of nonexempt assets to purchase or improve exempt property on the eve of bankruptcy, en Rutgers Law Review 3I (I978) 4.

Rushing, Danielle, Use it or lose it: grappling with classification of post-petition sale proceeds under chapter seven bankruptcy for consumer debtors in the lone star state, en St. Mary's Law Journal 49 (20I6) 4.

Ruz, Gonzalo, Nuevo derecho concursal chileno (Santiago, Thomson Reuters, 20I7), I.

Sebba, Rachel y Churchman, Arza, The Uniqueness of the Home, en Architecture and Behaviour 3 (I986) I.

SENDrA, Álvaro, El beneficio de exoneración del pasivo insatisfecho (Valencia, Tirant lo Blanch, 20I8).

Stephan, Guido, Stellungnahme zum Referentenentwurf eines Gesetzes zur Verkürzung des Restschuldbefreiungsverfahrens, zur Stärkung der Gläubigerrechte und zur Insolvenzfestigkeit von Lizenzen, en Zeitschrift für Verbraucher- und Privat-Insolvenzrecht (2012) 3.

Stiglitz, Joseph, Sen, Amartya y Fitoussi, Jean-Paul, Report by the Commission on the Measurement of Economic Performance and Social Progress (2009a) [visible en: https://bit.ly/3zL6k3Y]

Stiglitz, Joseph E., Sen, Amartya y Fitoussi, Jean-Paul, Informe de la comisión sobre la medición del desarrollo económico y del progreso social (2009b) [visible en: https://bit.ly/3h2Hmpx]

ТАВB, Charles, The scope of the fresh start in bankruptcy: collateral conversions and the dischargeability debate, en George Washington Law Review 59 (I990) $\mathrm{I}$.

TARvin, Timothy, Bankruptcy, relocation, and the debtor's dilemma: preserving your homestead exemption versus accepting the new job out of state, en Loyola University Chicago Law Journal 43 (2OII) I.

Vuкошісн, William, Debtors' exemption rights, en Georgetown Law Journal $62(1974) 3$. 
Whelan, Roger y Cohen, Mandy, Consumer bankruptcy reform: balancing the equities in chapter 13, en American Bankruptcy Institute Law Review 2 (1994) I.

Whitford, William, Secured creditors and consumer bankruptcy in the United States, en Osgoode Hall Law Journal 37 (1999) I.

Wiedemann, Rainer, Brauchen wir eine Reform der Verbraucherentschuldung?, en ZVI-Zeitschrift für Verbraucher- und Privat-Insolvenzrecht, (2004) II.

\section{SOBRE EL AUTOR}

Miguel Ángel Alarcón Cañuta es doctor en Derecho por la Universidad de Barcelona, España. Profesor asociado de la carrera de Derecho de la Universidad Arturo Prat, Sede Victoria, Chile. Su correo electrónico es mialarco@unap.cl. (1) https://orcid.org/oooo-0002-3284-0966. 
